\title{
The Voluminal Changes of Swim Bladder of Larval Red Sea Bream Pagrus major
}

\author{
Chikara KITAJIMA, ${ }^{* 1}$ Yasuo Tsúashima, ${ }^{* 2}$ and Masaru TANaKA ${ }^{* 3}$ \\ (Accepted October 29, 1984)
}

\begin{abstract}
Rearing experiments were made to determine the mechanism of diel swim bladder inflation and defiation in the red sea bream Pagrus major larvae. Swim bladder volume index $\left(\mathrm{V} / \mathrm{L}^{3} \cdot 10^{-6}\right)$ was found to increase remarkably with growth during the larval stage, and remain nearly constant in the juvenile stage.

The volume index was higher at night than in the day time under natural light conditions. However, under constant 24-h illumination such differences could not be observed. By changing the light conditions from dark to light, the volume index decreased to half within $2 \mathrm{~h}$. Furthermore, with the reverse changing from light to dark, it increased to maximum level about $1 \mathrm{~h}$ after the onset of dark. Sealing the water surface of the tank with a layer of liquid paraffin, did not interfere with swim bladder inflation under dark condition and larvae clearly displayed the diel rhythm of night-inflation and day-deflation under natural light conditions.

These results suggest that increase in the swim bladder volume in the physoclist species of red sea bream, is not caused by swallowing air at the water surface such as takes place in the physostome species of anchovy, but by the internal gaseous exchange mechanism of the swim bladder according to environmental light conditions.
\end{abstract}

Diel vertical migration, dusk-upward and dawn-downward, has been shown in several marine fish larvae $e^{1-4)}$ and recently field observations $^{3-7)}$ have demonstrated such diel migration in larval red sea bream Pagrus major. The diel vertical movement seems to be of importance as a depth-regulation mechanism ${ }^{8)}$ adaptive to conserving energy. It may also be significant for survival of fish larvae due to inevitable encounters with patches of food organisms. ${ }^{\text {? }}$ )

In some clupeoid larvae, night-inflation and daydeflation of swim bladder were shown in both field and laboratory studies., ${ }^{8}$ ) We have also obtained clear evidence that night-caught red sea bream larvae have larger swim bladders than daycaught larvae. The object of the present study was to examine voluminal changes of swim bladder of laboratory-reared larvae under different light conditions, and to relate this event to the mechanism of diel vertical migration.

\section{Materials and Methods}

Experiment I, Voluminal Changes of Swim Bladder with Growth

Fertilized red sea bream eggs were obtained from matured adults, spawned "naturally in the tanks on 24 April 1981. About twenty thousands eggs were maintained in a $1 \mathrm{k} l$ polycarbonate tank. Most larvae hatched out on 27 April. They were reared for the next 60 days using a sequential food menue, such as rotifer, Brachionus plicatilis, a benthic Harpacticoida, Tigriopus japonicus, and minced meat of krill and sand-eel. About 30 larvae were sampled at $1000 \mathrm{~h}$ every 3 or 4 days during the earlier $\mathbf{3 0}$ days, and on every 5 or 7 days during the latter 30 days. The maximum width and length of swim bladder were measured under a profile projector or on soft X-ray photographs. Swim bladder volume was calculated by using the prolate spheroid equation.*4 The value of swim bladder volume divided

*1 Shimabara Branch Station, Nagasaki Prefectural Institute of Fisheries, Shinden, Shimabara 855, Japan (北島 力: 長崎県水産圾政場島原分場).

*2. Sect. Fisheries, Tsushima Branch Office, Nagasaki Pref. Office, Izuhara, Nagasaki 817, Japan (塚島康 生: 長䗁県対馬支庁水産祼).

*3 Dept. Fisheries, Fac. Agriculture, Kyoto University, Kitashirakawa, Kyoto 606, Japan (田中 克: 京都大 学農学部).

*4 $V=4 / 3 \cdot a b^{2}, V=$ volume of swim bladder $\left(\mathrm{mm}^{3}\right), a=$ half the maximum bladder length $(\mathrm{mm}), \mathrm{b}=$ half the maximum bladder width (mm). 
by the cube of total length was defined as swim bladder volume index (VI).*

Experiment II. Voluminal Changes of Swim Bladder by Day and Night

About twenty thousands red sea bream larvae were reared in a $1 \mathrm{k} l$ transparent polycarbonate tank under natural light condition (natural light tank). 13 days after hatching, approximately half of them were transferred to a $1 \mathrm{k} l$ black wall polycarbonate tank. The latter tank was covered with a black screen to eliminate natural light, and illuminated continuously (24 h.) using a $40 \mathrm{~W}$ fluorescent lamp (illuminated tank). About 30 larvae were sampled from both experimental tanks every 2 days at day-time $(1000$ to $1100 \mathrm{~h})$ and at night-time (2000 to $2100 \mathrm{~h}$ ), and the total length, maximum bladder length and width were measured. From $1100 \mathrm{~h}$ of 29 May (31 days after hatching) to $1300 \mathrm{~h}$ of 30 May, 30 larvae were sampled every 2 to $6 \mathrm{~h}$ for examining the diel change of swim bladder volume.

Experiment III. Voluminal Changes of Swim Bladder under Alternating Light or Dark Conditions

On 9 May (15 days after hatching), about 300 larvae (average total length: $4.44 \pm 0.28 \mathrm{~mm}$ ) were transferred to a $100 l$ black polycarbonate tank covered with a black vinyl screen. After $6 \mathrm{~h}$ in the dark, larvae were exposed to natural daylight (about $6000 \mathrm{~lx}$ on the water surface). 30 larvae were sampled every one hour to examine the volume change of swim bladder. The voluminal change of swim bladder with time lapse of dark condition was examined using the reverse procedure under identical conditions.

Experiment IV. Swim Bladder Inflation Mechanism

To determine if the inflation of swim bladder at night was due to swallowing air at the water surface, 500 13-day larvae (average total length: $4.14 \pm 0.21 \mathrm{~mm}$ ) were transferred to two polycarbonate $100 l$ tanks. The surface of one tank was sealed with a $5 \mathrm{~mm}$ layer of liquid paraffin. During the period from $1300 \mathrm{~h}$ of 25 May to $1300 \mathrm{~h}$ of 26 May, 30 larvae were sampled from both tanks every 2 or $3 \mathrm{~h}$ to examine the difference of bladder volume between both tanks. Following this 300 larvae (16 days old, hatched out on $\mathbf{1 6}$ May, average total length: $6.95 \pm 0.52 \mathrm{~mm}$ ) were transferred to the same tanks (one was sealed,

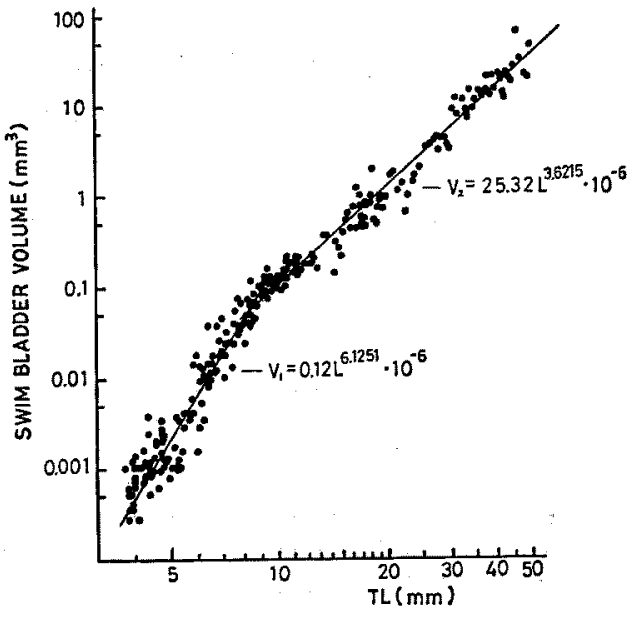

Fig. 1. Relation between the volume of swim bladder and the total length in larval and juvenile red sea bream.

the other was not). 30 larvae were sampled at 0900 to $1000 \mathrm{~h}$ from both tanks under natural light condition. After sampling, both tanks were put under complete dark condition and 30 larvae were sampled at 1500 to $1600 \mathrm{~h}$ from both tanks. Bladder volumes were measured and compared with the values of the former experiment.

\section{Results}

\section{Voluminal Changes of Swim Bladder with Growth}

The volume of swim bladder increased exponentially with growth of larvae and juveniles, as shown in Fig. 1. An inflection point was found at about $8.5 \mathrm{~mm}$ total length (TL). The relation between the volume of swim bladder $\left(\mathrm{V} \mathrm{mm}^{3}\right)$ and total length $(\mathrm{L} \mathrm{mm})$ could be expressed by

$$
\begin{aligned}
& V_{1}=0.12 \cdot L^{6.1251} \cdot 10^{-6} \quad(L<8.5 \mathrm{~mm}) \\
& V_{2}=25.32 \cdot L^{3.6215} \cdot 10^{-6} \quad(L \geqq 8.5 \mathrm{~mm})
\end{aligned}
$$

Expressing this correlation in terms of swim bladder volume index (Fig. 2), the increase in volume was rapid compared to that of body size during the larval stage. But, it tended to slow down in early juveniles larger than $10 \mathrm{~mm}$ (TL) and to attain a constant level in juveniles larger than $20 \mathrm{~mm}$ (TL).

Voluminal Changes of Swim Bladder by Day and Night

Swim bladder volume index (VI) increased with larval growth under both natural and illuminated

* $\mathrm{VI}=\mathrm{V} / \mathrm{L}^{3}, \mathrm{~L}=$ total length $(\mathrm{mm})$. 


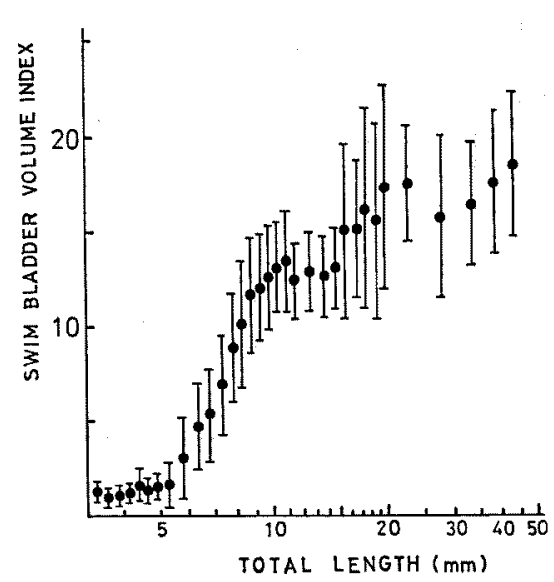

Fig. 2. Changes in the swim bladder volume index (mean $\pm \mathrm{SD}$ ) with growth of larval and juvenile red sea bream.

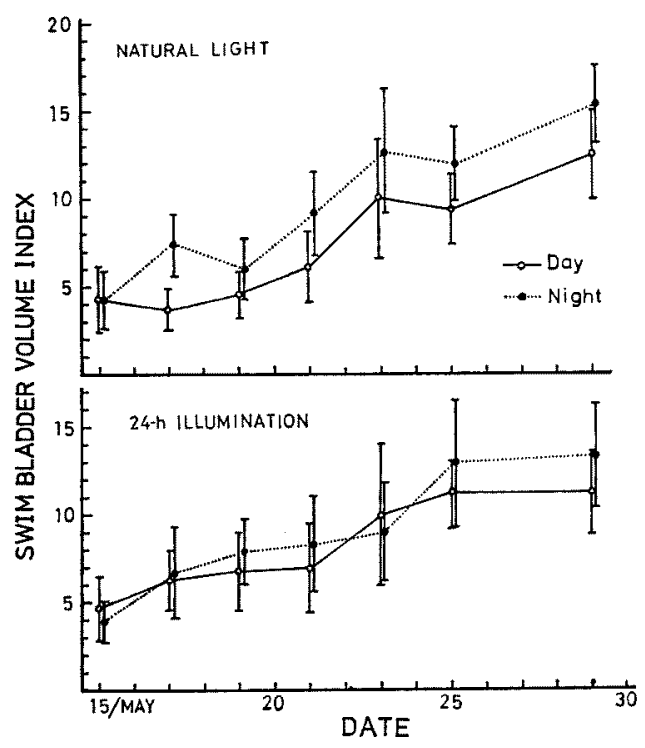

Fig. 3. Day-night differences in the swim bladder volume index (mean $\pm S D$ ) in red sea bream larvae reared under natural light (upper), and 24-h illumination condition with a $40 \mathrm{~W}$ fluorescence lamp (lower).

conditions. Mean night VI was clearly higher than mean day VI in the natural light tank (Fig. 3, upper). But such a day-night difference of VI could not be found in the illuminated tank (Fig. 3, lower).

Night VI was found to be higher than day VI

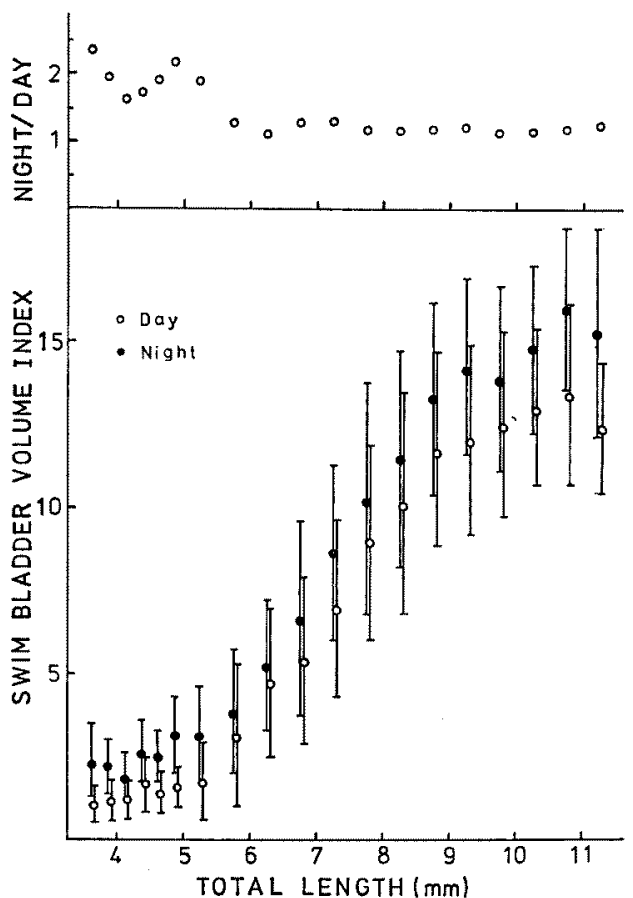

Fig. 4. Changes in the swim bladder volume index (mean \pm SD) in day and night with growth of reared red sea bream larvae. Upper panel showing the ratio of the mean volume index at night to that in day for each 0.25 or $0.5 \mathrm{~mm}$ size group of larvae. One dot represents a mean of 10 individuals.

under natural light conditions throughout the larval stage from 3.5 to $11 \mathrm{~mm}$ TL (Fig. 4, lower). But the ratio of mean night VI to day VI varied with larval growth, ranging from about 2 during earlier stages smaller than $5 \mathrm{~mm}$ TL to a constant level of 1.2 during the later stage (Fig. 4, upper).

Fig. 5 shows the diel change of VI of 31-day old larvae under natural light and 24-h illumination conditions. Under natural light, the VI tended to increase at dusk, maintain a higher level during night, and decrease at dawn remaining lower during day-time. Such diel changes of the VI could not be observed under $24-\mathrm{h}$ illumination condition.

Voluminal Changes of Swim Bladder under Alternating Light or Dark Conditions

During day-time, larvae markedly changed their swim bladder volume under alternating light and dark conditions. The VI decreased from about 3 


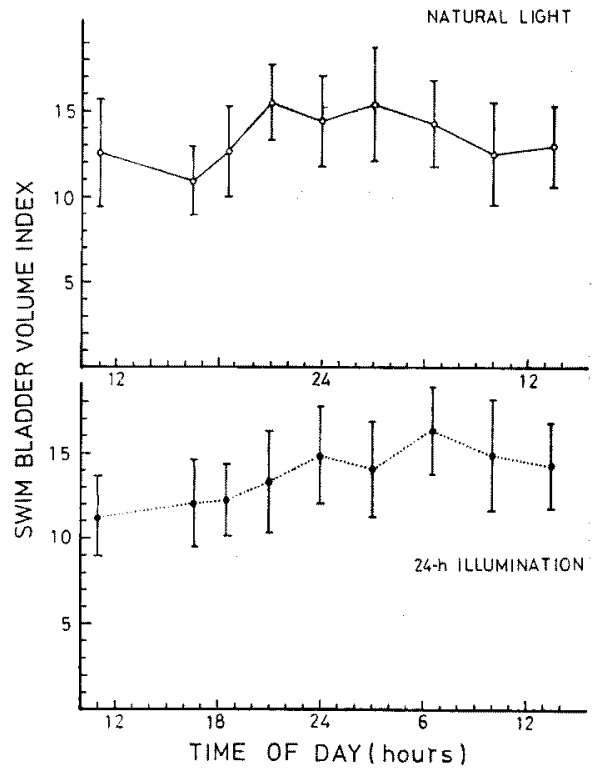

Fig. 5. Diel changes in the swim bladder volume index (mean $\pm S D$ ) in 31-day old larvae under natural light (upper) and 24-h illumination condition with a $40 \mathrm{~W}$ fluorescence lamp (lower).

to a constant level of 1.3 during $2 \mathrm{~h}$ after changing condition from dark to light (Fig. 6, upper) and increased from 1.7 to a constant level of 3 during $1 \mathrm{~h}$ after the reverse changing (Fig. 6 , lower).

\section{Swim Bladder Inflation Mechanism}

Fig. 7 shows the diel change in the swim bladder volume of 13-days larvae in the tank sealed with liquid paraffin and the non-sealed tank under natural light condition. The existence of the diel change in VI was confirmed in the liquid paraffin-sealed tank as well as in the non-sealed tank under natural light condition (Fig. 7). An additional experiment was made using 16-days larvae in both the sealed and non-sealed tanks under the light and dark conditions. The results are shown in Fig. 8. The swim bladder volume was clearly different from the dark to light conditions in the liquid paraffin-sealed tank as well as in the non-sealed tank. These two experiments suggest that the inflation of swim bladder was not due to swallowing air at the water surface, but probably to gas-exchange in the gas glands of the swim bladder.

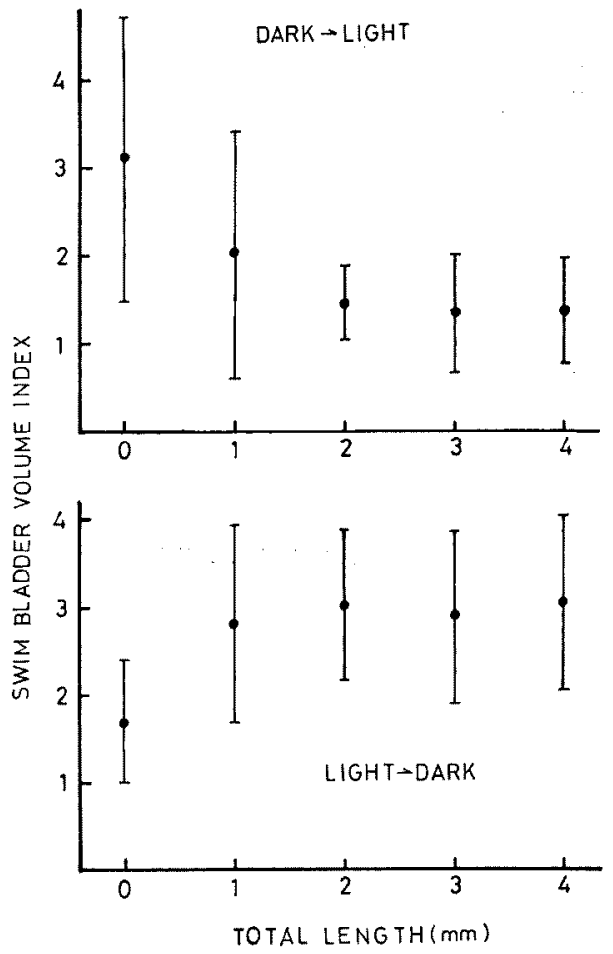

Fig. 6. Changes in the swim bladder volume index (mean \pm SD) of larval red sea bream with the changing conditions from dark to light (upper) and from light to dark (lower).

\section{Discussion}

The swim bladder of larval red sea bream begins to inflate and to be functional at about 3.5 to 4.0 $\mathrm{mm}$ TL during 5 to 10 days after hatching. ${ }^{10,11)}$ The initial gas in the swim bladder has been reported to originate from swallowing air. ${ }^{12)}$ The early swim bladder has an oval shape and is situated below the second and third myotome. From these on it elongates towards the tail to form a spheroid, finally terminating below the 10 th or 11th myotome at early juvenile stage. The shape of the swim bladder during juvenile stage scarcely change, while continuing to elongate anteriorposteriorly and bent slightly upward. As mentioned above, the voluminal change of swim bladder with growth showed an earlier increasing phase during the larval stage and later constant phase during the juvenile stage. These changes are well understood in the context of morphological development of the swim bladder.

The larval red sea bream displayed the diel 


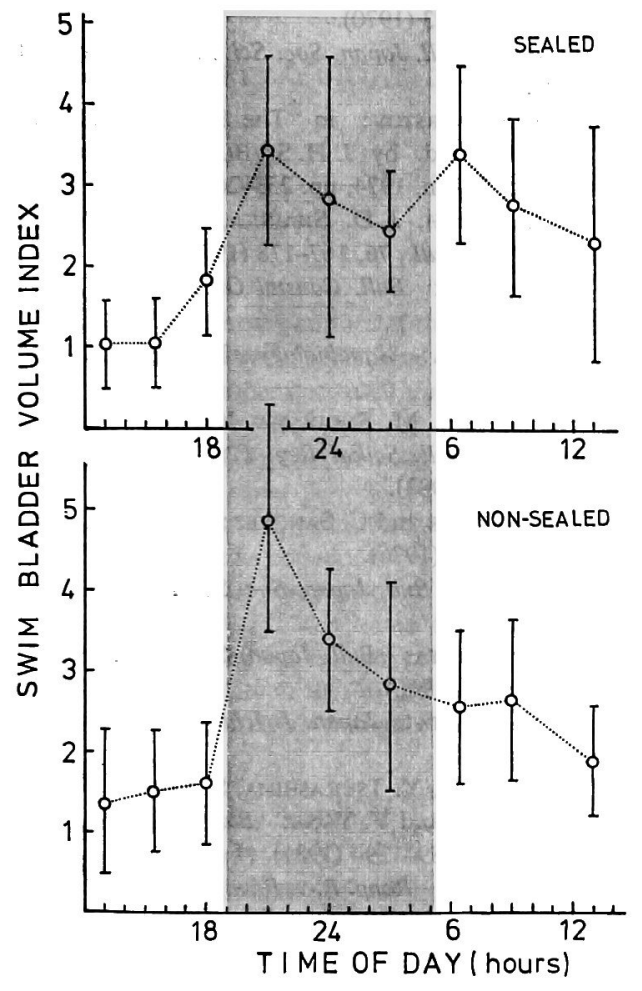

Fig. 7. Diel changes in the swim bladder volume index (mean $\pm S D$ ) of larval red sea bream (13 days after hatching) reared in the tank sealed with a layer of liquid paraffin (upper) and in the non-sealed tank (lower).

change in swim bladder volume, night-inflation and day-deflation, under rearing conditions. Also, in the sea, some authors have recognized the diel changes in larval habitats, night-upper and daydeeper. $^{5-7)}$ It is reasonable to assume that these diel vertical movements are closely related to the changes in swim bladder volume, consequently changing the organisms specific gravity.

Under laboratory conditions, previous experiments have shown the light condition to be the main environmental factor influencing the swim bladder volume. The swim bladder never exhibited any diel volume changes under 24-h illumination condition. However, even during the day-time the swim bladder inflated under the dark condition, and again deflated with changing from dark to light conditions. The time needed for complete inflation and deflation with changing light condition were about one hour from light to dark, and about two hours from dark to light.

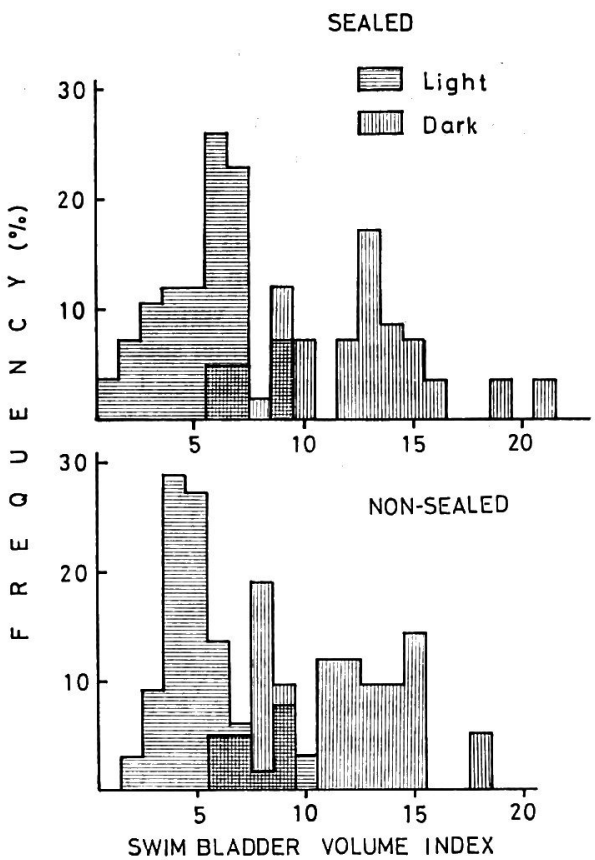

Fig 8. Comparison of frequency distributions of swim bladder volume index of larval red sea bream (16 days after hatching) in the liquid paraffinsealed (upper) and non-sealed tank (lower) under the light (lateral striped) and the dark condition (vertical striped).

Based on these results, it can be assumed that in the sea the larvae move upwards after sun-set with inflating bladders and downwards after sun-rise with deflating bladders. The diel vertical migration of fish larvae is likely to be affected by environmental light intensities. ${ }^{13,14)}$ As light intensity changes in the sea are gradual, it would be interesting to examine experimentally the threshold light intensities affecting swim bladder volume.

In the red sea bream, the pneumatic duct is differentiated from the dorsal wall of the rudimentary stomach during prelarval stage. Following its first inflation caused by the air, the duct closes and disappears about 10 to 12 days after hatching. ${ }^{10,11)}$ The gas glands and the rete mirabile develop with the disappearance of the pneumatic duct. The experiment using liquid paraffin sealed tanks clearly indicated that the diel inflation-deflation of swim bladder is caused by internal gas secretion and excretion, probably through the functions of both gas glands and rete mirabile.

In contrast with the larval red sea bream, the 
northern anchovy larvae larger than $10 \mathrm{~mm}$ inflated their swim bladders at night swallowing air at the water surface. ${ }^{8)}$ Also, in the present species the volume ratio of night-inflated bladders to daydeflated ones is only 1.2 to 2.0 , compared with about 5 in the anchovy. ${ }^{8)}$ The water-surface occurrence of larvae at night is distinct in the anchovy larvae, ${ }^{8, \theta)}$ but less so in the red sea bream larvae." Furthermore, the vertical migratory range is much wider in the former species than the latter. These prominent behavioral differences seem to be closely related to the physiological difference in the inflation mechanism, physostome and physoclist, and the extent of swim bladder inflation.

\section{Acknowledgements}

We thank Dr. S. Fuлta (present adress, Tokyo University of Fisheries) and Mr. T. ICHIKI, Nagasaki Prefectural Institute of Fisheries, for their helpful advices. We also thank Mr. G. Minkoff, Dunstaffnage Marine Research Laboratory, for his reading the manuscript.

\section{References}

1) T. Watanabe: Bull. Tokai Reg. Fish. Res. Lab.,
No. 62, 1-283 (1970).

2) H. IdA: Bull. Japan. Soc. Sci. Fish., 38, 891-994 (1972).

3) A. S. Seliverstov: in "The Early Life History of Fish" (ed. by J. H. S. BLAxter), SpringerVerlag, Berlin, 1974, pp. 253-262.

4) W. G. Smith, J. D. Sibunka, and A. Wells: U.S. Fish. Bull., 76, 167-178 (1978).

5) M. TANakA: Bull. Coastal Oceanogr., 17, 118130 (1980).

6) M. TANAKA: Aquabiology, No. 16, 379-386 (1981).

7) M. Tanaka, M. Sugryama, K. Tamal, and K. Mryan: Bull. Seikai Reg. Fish. Res. Lab., No. 59, 33-45 (1983).

8) J. R. Hunter and C. Sanchez: U.S. Fish. Bull., 74, 847-855 (1976).

9) I. UotanI: Bull. Japan. Soc. Sci. Fish., 39, 867876 (1973).

10) K. Yamashita: Bull. Japan. Soc. Sci. Fish., 32, 1006-1014 (1966).

11) K. YAMASHITA: Japan. J. Ichthyol., 29, 193-202 (1982).

12) C. Kutajima, Y. Tsukashima, S. Fujita, T. WATANABe, and Y. Yone: Bull. Japan. Soc. Sci. Fish., 47, 1289-1294 (1981).

13) R. J. Wood: Rapp. P.-v. Réun. Cons. Int. Explor. Mer, 160, 60-64 (1971).

14) D. SchNaCK: Rapp. P.-v. Réun. Cons. Int. Explor. Mer, 166, 114-123 (1974). 